\title{
Global Distribution of Tropical Deep Convection: Different Perspectives from TRMM Infrared and Radar Data
}

\author{
Chuntao Liu and Edward J. Zipser \\ Department of Meteorology, University of Utah, Salt Lake City, Utah \\ STEPHEN W. NeSBitT* \\ Department of Atmospheric Science, Colorado State University, Fort Collins, Colorado
}

(Manuscript received 27 March 2006, in final form 5 July 2006)

\begin{abstract}
Cold cloud features (CCFs) are defined by grouping six full years of Tropical Rainfall Measuring Mission (TRMM) infrared pixels with brightness temperature at $10.8-\mu \mathrm{m}$ wavelength $\left(T_{\mathrm{B} 11}\right)$ less than or equal to 210 and $235 \mathrm{~K}$. Then the precipitation radar (PR)-observed precipitation area and reflectivity profiles inside CCFs are summarized and compared with the area and minimum temperature of the CCFs. Comparing the radar with the infrared data, significant regional differences are found, quantified, and used to describe regional differences in selected properties of deep convective systems in the Tropics. Inside 4 million CCFs, $35 \%(57 \%)$ of cold cloud area with $T_{\mathrm{B} 11} \leq 235 \mathrm{~K}(210 \mathrm{~K})$ have rain detected by the PR near the surface. Only $\sim 1 \%$ of the area of $\mathrm{T}_{\mathrm{B} 11} \leq 210 \mathrm{~K}$ have $20 \mathrm{dBZ}$ reaching $14 \mathrm{~km}$. CCFs colder than $210 \mathrm{~K}$ occur most frequently over the west Pacific Ocean, but $20-\mathrm{dB} Z$ echoes extending above $10 \mathrm{~km}$ in this region are disproportionately rare by comparison to many continental regions. Ratios of PR-detected raining area to area of $T_{\mathrm{B} 11} \leq 235 \mathrm{~K}$ are higher over central Africa, Argentina, and India than over tropical oceans. After applying these ratios to the climatological Global Precipitation Index (GPI) tropical rainfall estimates, the regional distribution is more consistent with the rainfall retrieval from the PR. This suggests that the discrepancy between GPI- and PR-retrieved rainfall can be partly explained with the nonraining anvil. Categorization of CCFs based on the minimum $T_{\mathrm{B} 11}$, size of CCFs, and 20-dBZ heights demonstrates that 20 -dBZ echoes above $17 \mathrm{~km}$ occur most frequently over land, while the coldest clouds occur most frequently over the west Pacific. The vertical distances between the cloud-top heights determined from $T_{\mathrm{B} 11}$ and PR 20-dBZ echo-top heights are smaller over land than over ocean and may be considered as another proxy for convective intensity.
\end{abstract}

\section{Introduction}

Deep convection plays a crucial role in precipitation, heat transfer (Riehl and Malkus 1958), and tropospherestratosphere exchange (Holton et al. 1995; Sherwood and Dessler 2000) in the Tropics. The global and regional characteristics of deep convection have been investigated using a variety of observing tools including

\footnotetext{
* Current affiliation: Department of Atmospheric Sciences, University of Illinois at Urbana-Champaign, Urbana, Illinois.
}

Corresponding author address: Dr. Chuntao Liu, Department of Meteorology, University of Utah, 135S 1460E, Rm. 819, Salt Lake City, UT 84112-0110.

E-mail: liuct@met.utah.edu satellite infrared (IR) images (e.g., Mapes and Houze 1993; Hall and Vonder Haar 1999; Gettelman et al. 2002), microwave measurements (e.g., Mohr and Zipser 1996; Toracinta and Zipser 2001; Jiang et al. 2004; Hong et al. 2005), and ground-based (e.g., Heymsfield and Fulton 1988; Cifelli et al. 2002), ship-borne (e.g., DeMott and Rutledge 1998), airborne (e.g., Heymsfield et al. 1996) and space-borne (e.g., Nesbitt et al. 2000; Petersen and Rutledge 2001; Schumacher and Houze 2003; Cecil et al. 2005; Liu and Zipser 2005; Nesbitt et al. 2006) radars.

However, various instruments respond to properties of deep convection in different ways. Cloud-top brightness temperatures from IR images give reliable cloud coverage with high horizontal and temporal resolution (Rossow and Schiffer 1999). Studies using radar and passive microwave observations can give direct indica- 

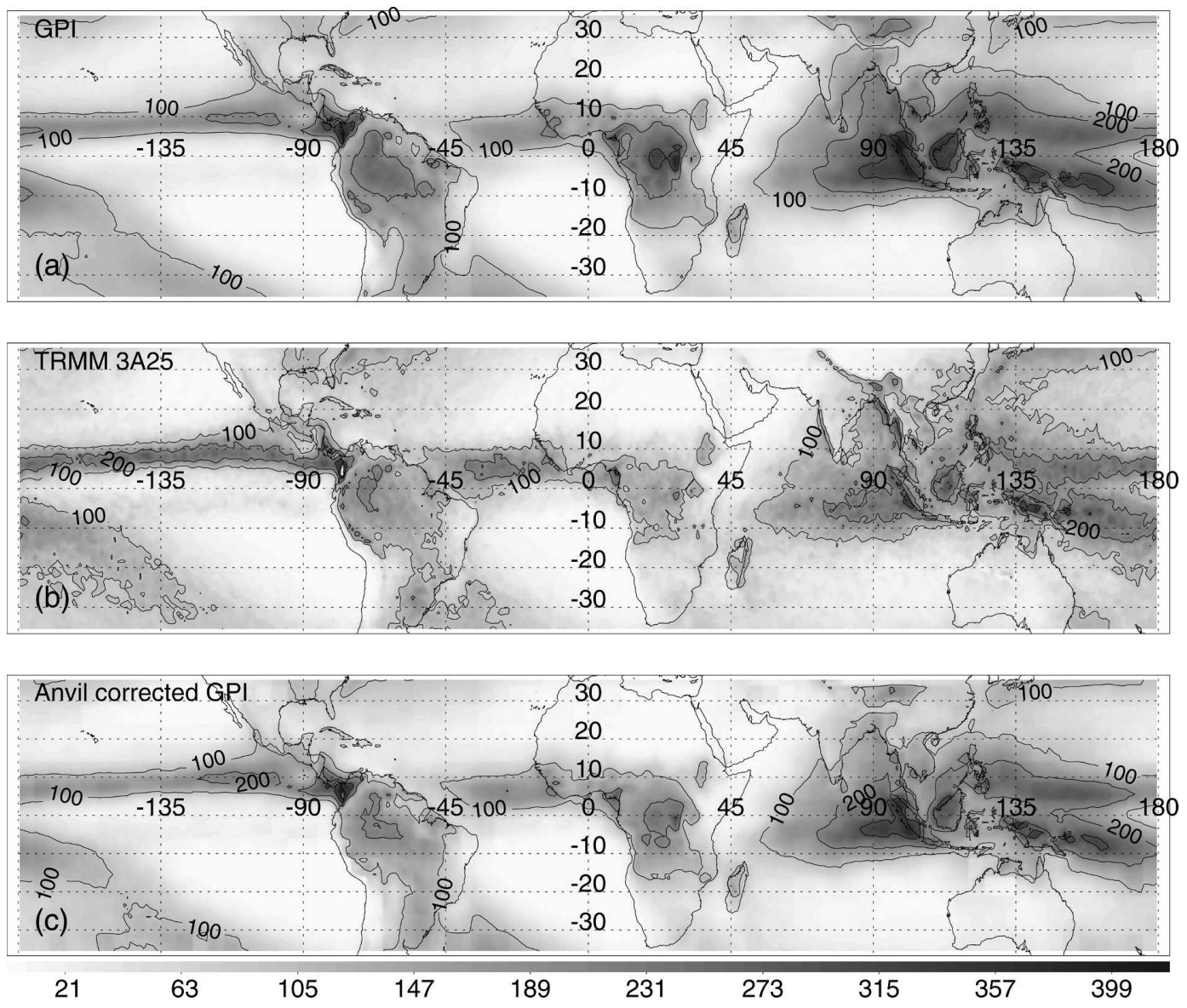

FIG. 1. The 6-yr (1998-2004; see text) average of monthly rain rate estimates from (a) GPI, (b) TRMM 3A25, and (c) GPI after corrected with ratio of anvil area (see section 3a).

tions of the intensity of convection. However, few studies have quantitatively investigated the relationship between high, cold anvil clouds and the intensity of the convection that produced them. Combining IR images and ground-based, shipborne, and airborne radars have provided case studies of convection and clouds (e.g., Heymsfield and Fulton 1988; Heymsfield et al. 1996; Cifelli et al. 2002; Cifelli et al. 2007), but the limited temporal or spatial coverage necessarily confines them to a small sample of tropical deep convection.

Liu and Zipser (2005) and Zipser et al. (2006), by focusing on observations that are direct indicators of the intensity of convection, find that intense convection in the Tropics is concentrated over land areas. Yet studies using IR as a primary data source (e.g., Gettelman et al. 2002) often find that the tropical west Pacific Ocean has the greatest concentration of cold, high clouds. The question arises whether these are contradictory results, or whether they can be explained as observations of different aspects of deep convective cloud systems that may have different properties.
The Tropical Rainfall Measuring Mission (TRMM) satellite (Kummerow et al. 1998) measures collocated visible and infrared radiances from the Visible and Infrared Scanner (VIRS), microwave radiance from the TRMM Microwave Imager (TMI), radar reflectivity from the Precipitation Radar (PR), and flashes from the Lightning Imager Sensor (LIS). It provides a unique opportunity to investigate tropical deep convective systems from two different perspectives aboard TRMM: IR images from VIRS and radar reflectivity from the PR using six years of TRMM measurements. To be specific, in this paper we address the following questions:

1) It is known that there are surface rainfall retrieval biases between estimates from IR-only techniques and radar-only techniques (e.g., McCollum et al. 2000). As shown in Figs. 1a,b, 6-yr-averaged monthly rainfall from the Global Precipitation Index (GPI; Joyce and Arkin 1997) overestimates the surface rainfall over the west Pacific and central Af- 


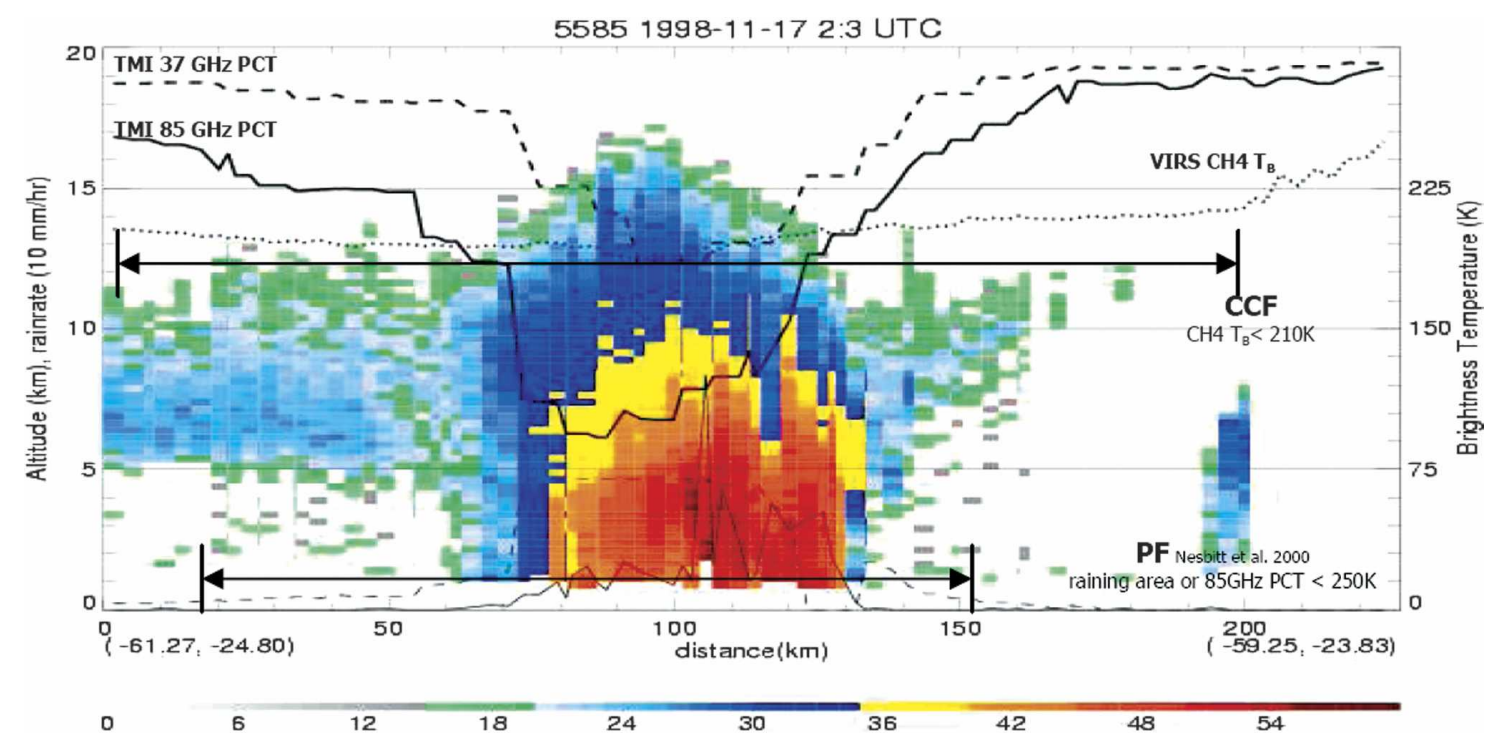

FIG. 2. Example of the definitions of precipitation features (Nesbitt et al. 2000) and cold cloud features (CCF $\leq 210 \mathrm{~K}$ ) from a TRMM orbit over Argentina in 1998. Thin dashed line is the TRMM 2A12 (retrieved from TMI) rainfall rate. Thin solid line is the TRMM 2A25 (retrieved from PR) rainfall rate.

rica, and underestimates the surface rainfall over the east Pacific relative to the climatology of TRMM PR retrievals (3A25). By examining the near-surface rain detected by the PR inside a cold cloud area in VIRS IR images, we believe that the results will help elucidate the discrepancies between IR and PR rainfall retrievals on a regional basis.

2) Do deeper and colder clouds always indicate more intense convection? Where can we find the coldest clouds in the Tropics? How far below the IR cloud top is the radar echo top, and how are the differences distributed globally? We will use the VIRS and PR database to calculate these differences and seek physical explanations for the observations.

First, six years of TRMM VIRS and PR data are matched at PR resolution within the PR orbit swath. Then cold cloud features are defined based on the VIRS IR temperature. Finally, the statistics of PR reflectivity and IR temperature features and their differences are summarized and compared. Section 2 describes the definitions, data, and analysis method. Results and discussion are given in section 3 .

\section{Data and methods}

This section first introduces how deep convective systems are defined with TRMM VIRS data and then describes the TRMM data combination, grouping, and construction of the University of Utah TRMM database.

\section{a. Definitions of deep convection from TRMM VIRS}

The traditional way to define deep convection from IR measurements is finding pixels with brightness temperatures colder than a given temperature threshold from IR images. This threshold could be $208 \mathrm{~K}$ (Mapes and Houze 1993; Chen et al. 1996; Hall and Vonder Haar 1999), 210 K (Zuidema 2003), 218 K (Machado et al. 1998), $230 \mathrm{~K}$ (Tian et al. 2004), or cold point tropopause temperature (Gettelman et al. 2002). This method detects convective clouds reaching high altitude with cold brightness temperature at IR wavelengths. However, besides the convective region, cold nonraining anvil clouds or thick cirrus are included in the definition as well. One primary advantage of TRMM observations is that not only may the area of cold clouds be defined for any brightness temperature threshold at IR wavelength, but also the raining area and radar reflectivity vertical structure details beneath the IR cloud tops may be obtained. This is demonstrated in an example in Fig. 2. VIRS measures depressed brightness temperatures at $10.8-\mu \mathrm{m}$ wavelength $\left(T_{\mathrm{B} 11}\right)$ from above deep convection. The large optical depth of precipitation-sized ice particles in the convective clouds causes strong depression of brightness temperatures at TMI $85 \mathrm{GHz}$ and thus appears as low polarization corrected temperature (PCT; Spencer et al. $1989)$. High vertical resolution $(\sim 250 \mathrm{~m})$ radar reflectivity from the PR provides detailed vertical structure of the storm including the anvil region. Intense convec- 
tion, able to produce more condensate in the mixedphase and cold-phase region and thus loft more and/or larger ice particles to higher altitude, has increased radar reflectivity at altitude, as well as increased scattering of $85-\mathrm{GHz}$ radiance out of the TMI field of view. Thus, intense convection contains higher PR high echotop heights (ETHs) and lower 85-GHz PCTs relative to weaker convection (Nesbitt et al. 2000). Also there are two independent surface rain estimates available: the retrieval from PR near-surface reflectivity with the rain-profiling algorithm (2A25: Iguchi et al. 2000) and the retrieval from TMI brightness temperatures at different wavelength with the Goddard-profiling algorithm (2A12: Kummerow et al. 2001).

Our approach utilizes two temperature thresholds to define cold cloud features (CCFs) with the following steps:

- First, the VIRS pixels $(2 \times 2 \mathrm{~km}$ at nadir $)$ are matched with PR pixels $(4.3 \times 4.3 \mathrm{~km}$ at nadir $)$ within the PR swath.

- Second, the contiguous pixels with $T_{\mathrm{B} 11}$ colder than 210 or $235 \mathrm{~K}$ are grouped as CCFs (see example in Fig. 2). At least four pixels are required for each CCF, so cold clouds with area less than $75 \mathrm{~km}^{2}$ below each threshold are not considered.

- Within the area of each CCF, properties of precipitation and convective intensity of the CCF are summarized with the following variables: area of the cloud reaching high altitudes inferred by the number of pixels with $T_{\mathrm{B} 11} \leq 210$ and $235 \mathrm{~K}$; area of the CCF with large amount of total column ice inferred by TMI $85-\mathrm{GHz} \mathrm{PCT} \leq 250,225$, and $200 \mathrm{~K}$; and area inside CCF detected by PR at different altitudes inferred by the number of pixels with PR $20 \mathrm{~dB} Z$ at 6 , 10 , and $14 \mathrm{~km}$. Here $20 \mathrm{dBZ}$ is arbitrarily chosen for keeping a constant lower limit of PR reflectivity before and after the TRMM satellite orbit boosting in August 2001. Because of the sixth-power dependence of radar reflectivity on particle size, echoes of $20 \mathrm{dBZ}$ are considerably stronger than anything observed in cirrus clouds and essentially assure that there are large, precipitation-sized particles present at altitude, evidence of strong convective updrafts; number of pixels with surface rain rate $>0 \mathrm{~mm}$ $\mathrm{h}^{-1}$ from TRMM 2A25 and 2A12 retrievals; total flash counts from the LIS; minimum $T_{\mathrm{B} 11}$; minimum TMI 85-GHz PCT, 37-GHz PCT; maximum height (MSL/above earth ellipsoid) of PR 20, 30, and 40 $\mathrm{dBZ}$.

- Last, horizontal wind components and thermodynamic variables including temperatures, and geopotential heights at standard pressure levels for each
CCF, are obtained by temporal and spatial interpolation of National Centers for Environmental Prediction (NCEP) reanalysis data to the time and geographic center of each CCF.

After applying the definition to the version 6 TRMM data from 1998 to 2004, CCFs are identified and their properties recorded in the University of Utah database. Owing to instrument problems in September and October 2002 and the satellite orbit boost in August 2001, some VIRS measurements are missing or not reliable. For these reasons, the 6-yr data from 1998-2001 and 2003-04 are used in this study, replacing August 2001 with August 2002 data.

\section{b. University of Utah TRMM database}

The University of Utah TRMM database is developed based on the framework of precipitation features (PFs) defined by Nesbitt et al. (2000). Using this definition, global distribution of storms with LIS-detected lightning (Cecil et al. 2005), deep convection reaching the tropical tropopause layer (Liu and Zipser 2005), rainfall production and convective organization (Nesbitt et al. 2006), and extreme thunderstorms (Zipser et al. 2006) have been studied. With NCEP data, gridlevel data processing and adding a definition of CCFs, current database construction represents three levels of processing of the TRMM data, as shown in Fig. 3.

- Level-1 data are produced with a combination of the version-6 1B01, 1B11, 2A12 (Kummerow et al. 2001), 2A23, 2A25 (Iguchi et al. 2000), and LIS granules, TMI-PR-LIS-VIRS nearest-neighbor collocation, TMI-PR parallax correction [in the collocation procedure, the TMI data are shifted one scan $(\sim 14 \mathrm{~km})$ toward the satellite to account for the "parallax" between the two instruments caused by the PR and TMI difference in viewing angles] and PF and CCF grouping (see example in Fig. 2). The output data are saved for each satellite orbit.

- Using level-1 data, the statistics, such as volumetric rain, flash counts, and maximum height of $20 \mathrm{dBZ}$, etc., for each PF and CCF are derived. Then, collocations with NCEP-National Center for Atmospheric Research (NCAR) reanalysis (Kistler et al. 2001) parameters and monthly combination of orbital data are performed to obtain the level-2 PF and CCF data.

- To process level-3 data, first the monthly statistics of PF properties in level- 2 data are derived on a $1^{\circ} \times 1^{\circ}$ grid. Then, the precipitation estimates from GPI (Joyce and Arkin 1997), Global Precipitation Climatology Centre (GPCC; Rudolf 1993), Global Precipitation Climatology Project (GPCP; Huff- 


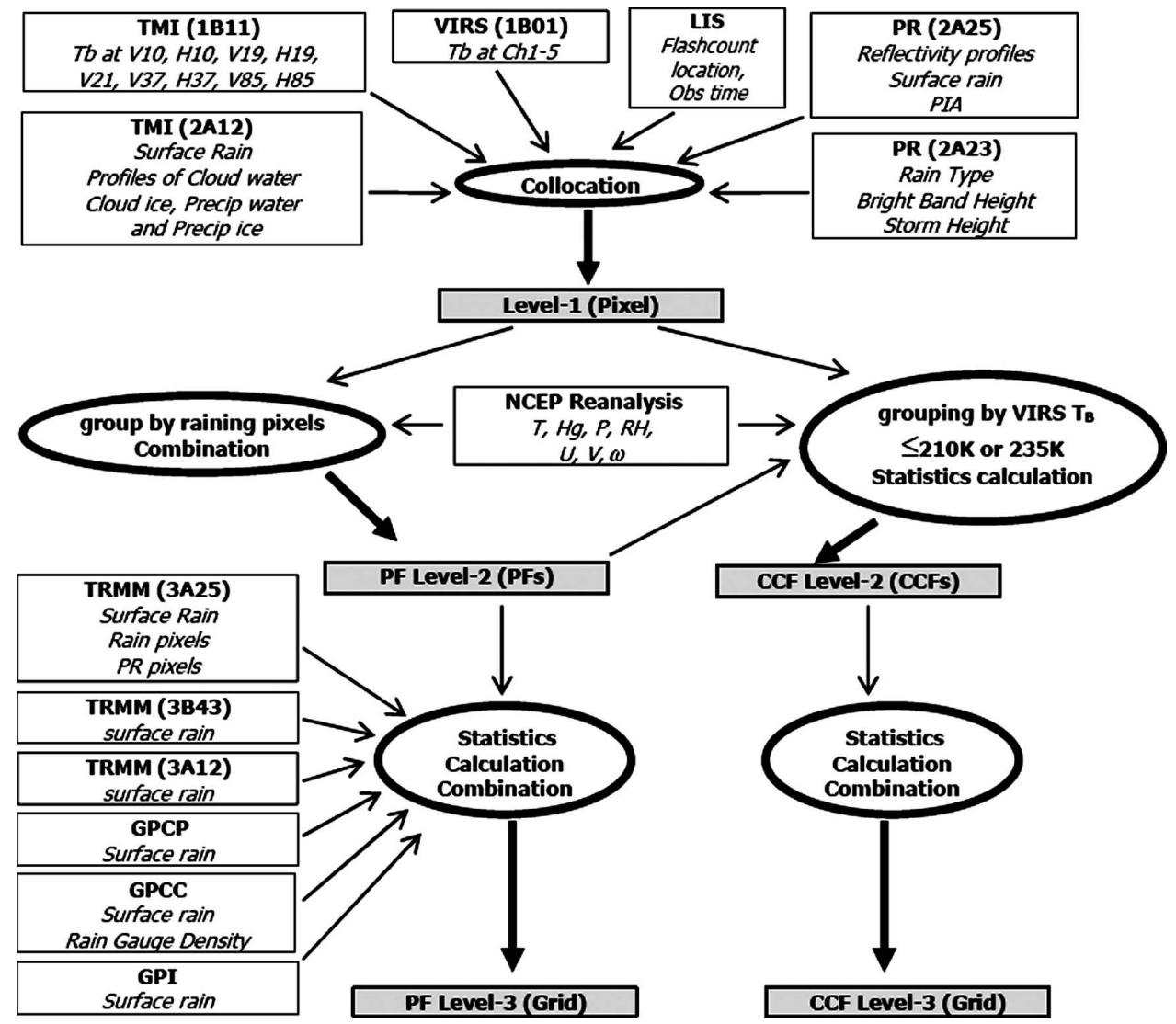

FIG. 3. University of Utah TRMM database construction flowchart.

man et al. 2001), and TRMM 3A25 and 3B43 are included. After combination, level-3 PF data include the precipitation estimates from different sources and the statistics of PFs that contributed to the precipitation on $1^{\circ} \times 1^{\circ}$ grids. Using a similar procedure, level-3 CCF data are produced with the statistics of $\mathrm{CCFs}$ on a $5^{\circ} \times 5^{\circ}$ grid.

\section{Results and discussion}

Within the dataset, a total of 4154988 CCFs were grouped with $T_{\mathrm{B} 11} \leq 235 \mathrm{~K}$, and $724993 \mathrm{CCFs}$ were grouped with $T_{\mathrm{B} 11} \leq 210 \mathrm{~K}$ between $36^{\circ} \mathrm{N}$ and $36^{\circ} \mathrm{S}$. The area of $20-\mathrm{dBZ}$ radar echo at different altitudes, cold TMI $85-\mathrm{GHz}$ PCT, and surface rain from CCFs from the full database and the subset from $20^{\circ} \mathrm{N}$ to $20^{\circ} \mathrm{S}$ are listed in Table 1 . From $20^{\circ} \mathrm{N}$ to $20^{\circ} \mathrm{S}$, only $0.93 \%$ of $T_{\mathrm{B} 11} \leq 210 \mathrm{~K}$ area have any $20-\mathrm{dB} Z$ echo reaching 14 $\mathrm{km}$. This compares with the finding of $\sim 0.5 \pm 0.25 \%$ Tropics with $T_{\mathrm{B} 11}$ area colder than the cold point tropopause reported by Gettelman et al. (2002) and $\sim 0.008 \%$ fractional coverage in the Tropics with 20 $\mathrm{dBZ}$ echo above $14 \mathrm{~km}$ reported by Liu and Zipser
(2005). Only $35 \%$ (57\%) of the area of clouds with $T_{\mathrm{B} 11}$ $\leq 235 \mathrm{~K}(210 \mathrm{~K})$ have rain detected by the PR. Note that the PR reflectivity threshold of $17 \mathrm{dBZ}$ (Kummerow et al. 1998) would omit some of the light rain area in the CCFs. The TMI detects a slightly larger raining area $\left(40 \%\right.$ under $T_{\mathrm{B} 11} \leq 235 \mathrm{~K}$ and $65 \%$ under $\left.T_{\mathrm{B} 11} \leq 210 \mathrm{~K}\right)$. It is reasonable to relate the regional differences in the fraction of $T_{\mathrm{B} 11} \leq 235 \mathrm{~K}$ nonraining area to the regional differences in rainfall estimations from IR and radar. Therefore, we now examine the global distribution of the ratio of PR-detected precipitation area to the cold cloud coverage.

\section{a. Nonraining cold clouds and their impact on GPI}

To obtain the global distribution of the cold cloud, the area with $T_{\mathrm{B} 11} \leq 235 \mathrm{~K}$ inside the PR swath is accumulated in $5^{\circ} \times 5^{\circ}$ boxes from the CCF database. Then, the accumulated areas are normalized with TRMM 3A25 total pixel numbers to remove the TRMM sampling bias with latitude. Finally, the percentage contribution of each $5^{\circ} \times 5^{\circ}$ box is calculated by dividing by the total from all the boxes (Fig. 4a). This procedure is applied to pixels with PR 2A25 rain 


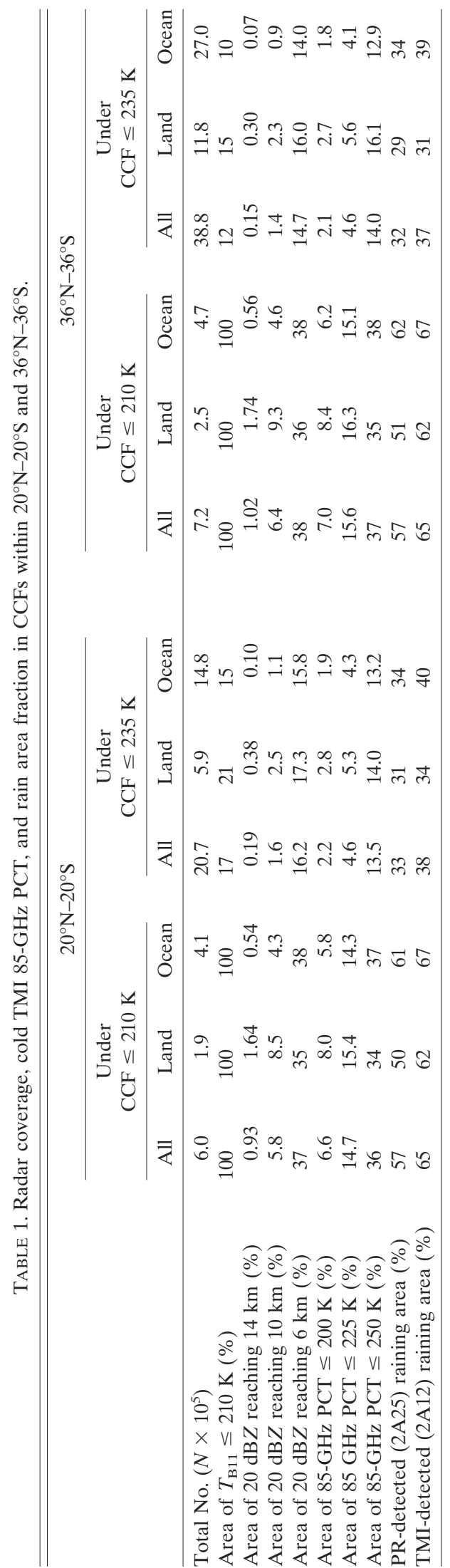

inside CCFs to get the distribution of raining area under $235 \mathrm{~K}$ (Fig. 4b). The differences are expressed as a ratio of the accumulated raining area to the accumulated cold cloud area in Fig. 4d. A first look of the distributions of 235-K clouds in Fig. 4a and raining area in Fig. 4b seem similar. There is a large contribution of both cold cloud and raining area in the tropical west Pacific, the Amazon, Central Africa, and the ITCZ oceans. However, there are large differences in the proportion of raining area shown in Fig. 4d. A smaller proportion of raining area is found over Central Africa, Argentina, India, the northern boundary of the ITCZ of both the east Pacific and the Atlantic. Larger proportions of raining area are found over the southern boundary of the ITCZ, especially over the Atlantic.

The differences of GPI and radar precipitation estimates may come from four sources: 1) overestimation of GPI due to the nonraining area under $235 \mathrm{~K}$ clouds; 2) unrealistic assumed constant rainfall rate in GPI while actual mean conditional rain rates vary (e.g., Nesbitt et al. 2006); 3) rainfall from clouds warmer than 235 $\mathrm{K}$; and 4) errors in the PR rainfall algorithm. Here we only focus on the first possibility, evaluating the impact of the nonraining area to the rainfall estimates by GPI.

A rough correction with two steps is applied to a 6-yr average of GPI monthly rain in Fig. 1. First, GPI monthly rain is simply multiplied by the raining area ratio from Fig. 4d. Then normalizing with total rain volume from $3 \mathrm{~A} 25$, the total amount of rain is consistent with the $3 \mathrm{~A} 25$. After the correction, correlation between GPI and 3A25 increases from 0.88 to 0.92 (Fig. 5). The corrected GPI shows less overestimation over Africa, while showing little change over the east Pacific and Atlantic ITCZ (Fig. 1c). This implies that nonraining anvil could be one main reason for some of the discrepancy between GPI and 3A25 over land regions where the ratio of anvil area to raining area is higher.

Explicit regional differences in nonraining anvil area are shown more clearly in Fig. 6. The raw differences between GPI and PR rainfall (Fig. 6a) are large and mostly of the same sign. Normalization (Fig. 6b) of GPI simply reduces GPI by a constant percentage. Correction for nonraining anvil (Fig. 6c) tends to reduce the extremes of both signs. (This is consistent with Fig. 5, which shows that the correction reduces the number of outliers.) Figure $6 \mathrm{~d}$ shows that the correction generally increases the GPI estimates over oceans and reduces them over land, generally consistent with known biases of GPI.

However, it is also clear that this result is only one of the reasons for the differences between GPI and radar rainfall estimates. To improve the unrealistic constant rainfall rate in GPI, some IR rainfall estimation tech- 

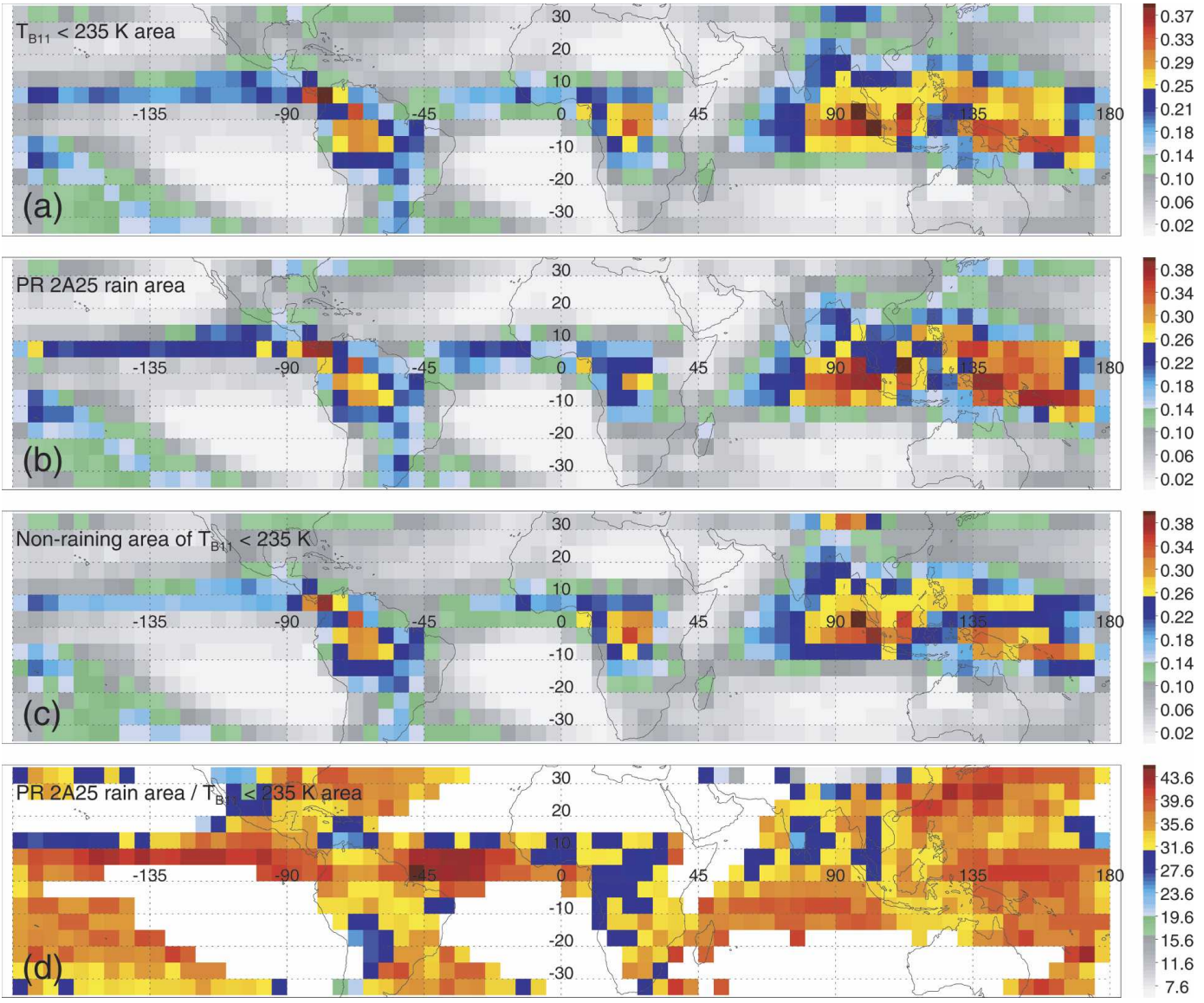

FIG. 4. (a) Global distribution of area of $T_{\mathrm{B} 11} \leq 235 \mathrm{~K}$ from CCFs $(\leq 235 \mathrm{~K})$. The area in each $5^{\circ} \times 5^{\circ}$ bin has been divided by TRMM 3A25 total pixel number to remove the sampling bias. Units are percent. (b) As in (a) but for the area with PR 2A25 rain from CCFs $(\leq 235 \mathrm{~K})$. (c) As in (b), but for the area without PR $2 \mathrm{~A} 25$ rain. (d) Ratio of area with PR $2 \mathrm{~A} 25$ rain to area of $T_{\mathrm{B} 11} \leq 235 \mathrm{~K}$ in $5^{\circ} \times 5^{\circ}$ bins.
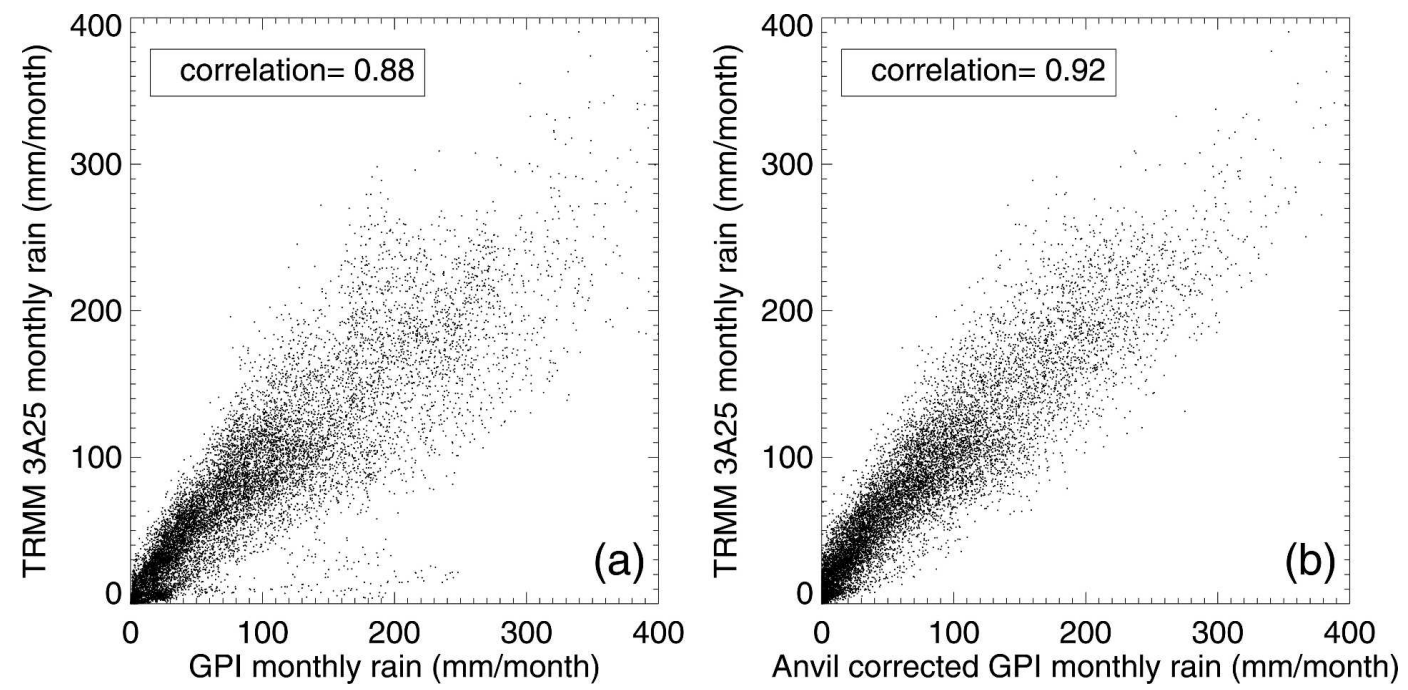

FIG. 5. (a) Scatter diagram of the 6-yr average monthly rain from GPI and TRMM $3 \mathrm{~A} 25$ in $1^{\circ} \times 1^{\circ}$ boxes between $20^{\circ} \mathrm{S}$ and $20^{\circ} \mathrm{N}$. (b) Similar to (a) except applying a correction to the $T_{\mathrm{B} 11} \leq 235 \mathrm{~K}$ ratio from Fig. $4 \mathrm{~d}$ to the GPI rain. 
GPI - TRMM $3 A 25$ (mm/month)
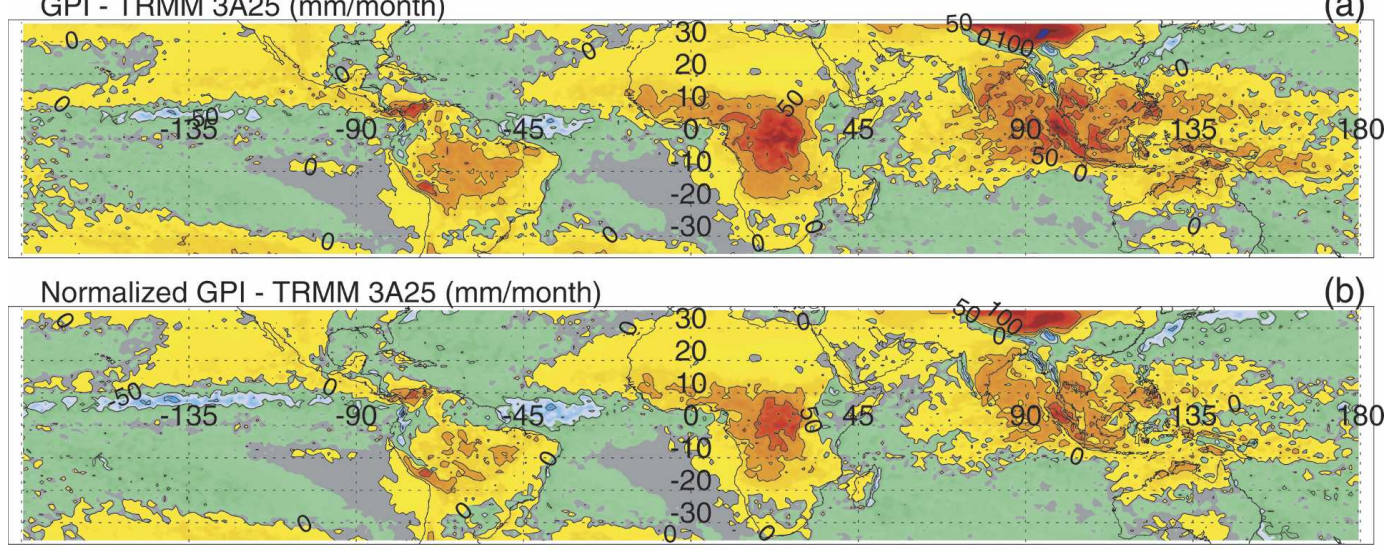

Anvil corrected GPI - TRMM 3 A25 ( $\mathrm{mm} /$ month)

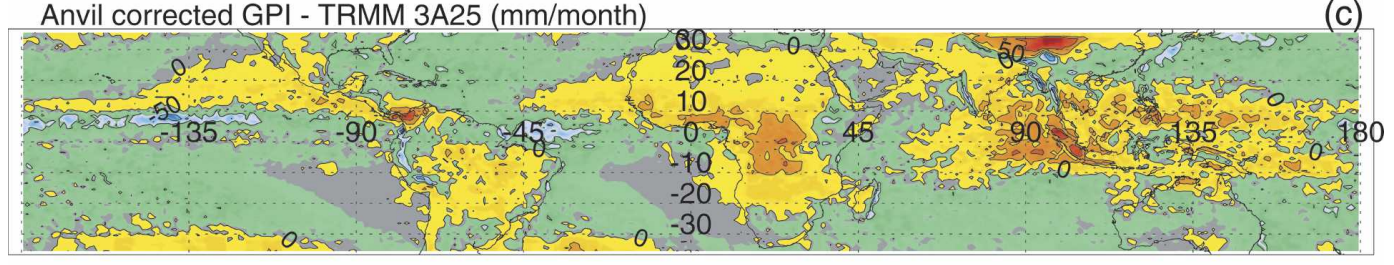

Anvil corrected GPI - Normalized GPI (mm/month)

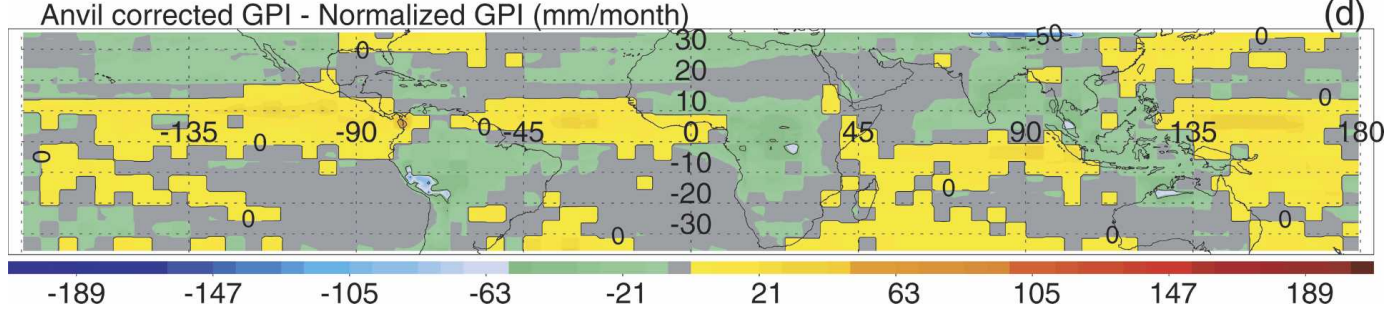

FIG. 6. Differences between (a) unadjusted GPI and 3A25 rain; (b) normalized GPI and 3A25 rain; (c) normalized GPI corrected for fractional area with IR $T_{b} \leq 235 \mathrm{~K}$ without PR-detected near-surface rainfall and 3A25 rain; and (d) net adjustment in normalized GPI rain resulting from correcting for nonraining areas IR $T_{b} \leq 235 \mathrm{~K}$.

niques (e.g., Vicente et al. 1998) directly relate cloudtop temperatures to the surface rainfall rates. However, the global applicability of these relations needs investigation because precipitation systems vary significantly in different regions (Nesbitt et al. 2006). Next, we examine relationships between the vertical structure of deep convection and cloud-top temperature on a regional basis.

\section{b. Global distribution of deep convection top viewed by $P R$ and VIRS}

Using the same procedure as for $T_{\mathrm{B} 11} \leq 235 \mathrm{~K}$, the global distribution of area with $T_{\mathrm{B} 11} \leq 210 \mathrm{~K}$ and PR 20 $\mathrm{dBZ}$ reaching $6 \mathrm{~km}, 10 \mathrm{~km}$, and $14 \mathrm{~km}$ is generated from the CCF database $\left(T_{\mathrm{B} 11} \leq 235 \mathrm{~K}\right)$ and shown in Fig. 7. While large areas of cold cloud area are found both over ocean and land; the CCFs with the largest fractional area of $20-\mathrm{dB} Z$ echoes extending above 10 $\mathrm{km}$ and especially above $14 \mathrm{~km}$ are found over land.
There is a large fractional area of $210-\mathrm{K}$ clouds over the west Pacific. However, 20-dBZ echoes above $10 \mathrm{~km}$ cover a relatively small fractional area in this region.

To investigate the CCF database $\left(T_{\mathrm{B} 11} \leq 210 \mathrm{~K}\right)$ further, it is categorized by rarity of minimum $T_{\mathrm{B} 11}, 210-\mathrm{K}$ area, maximum $20-\mathrm{dBZ}$ height, and the area of $20 \mathrm{~dB} Z$ at $10 \mathrm{~km}$. The locations of CCFs in each category are shown with different colors in Fig. 8. Apparently, the coldest and largest $210-\mathrm{K}$ area CCFs are found frequently over the west Pacific. Consistent with Fig. 7, more CCFs with $20-\mathrm{dBZ}$ echo reaching very high altitude occur over land. The coldest CCFs are found more frequently over the northern west Pacific (Fig. 8a), but the largest cold cloud areas are found over the southern west Pacific (Fig. 8c). Large areas of $20 \mathrm{dBZ}$ at $10 \mathrm{~km}$ indicate large and intense convective systems. Central Africa, Argentina, Texas, and the Bay of Bengal with large areas of $20 \mathrm{dBZ}$ at $10 \mathrm{~km}$ are consistent with the locations of strongest thunderstorms (Zipser et al. 

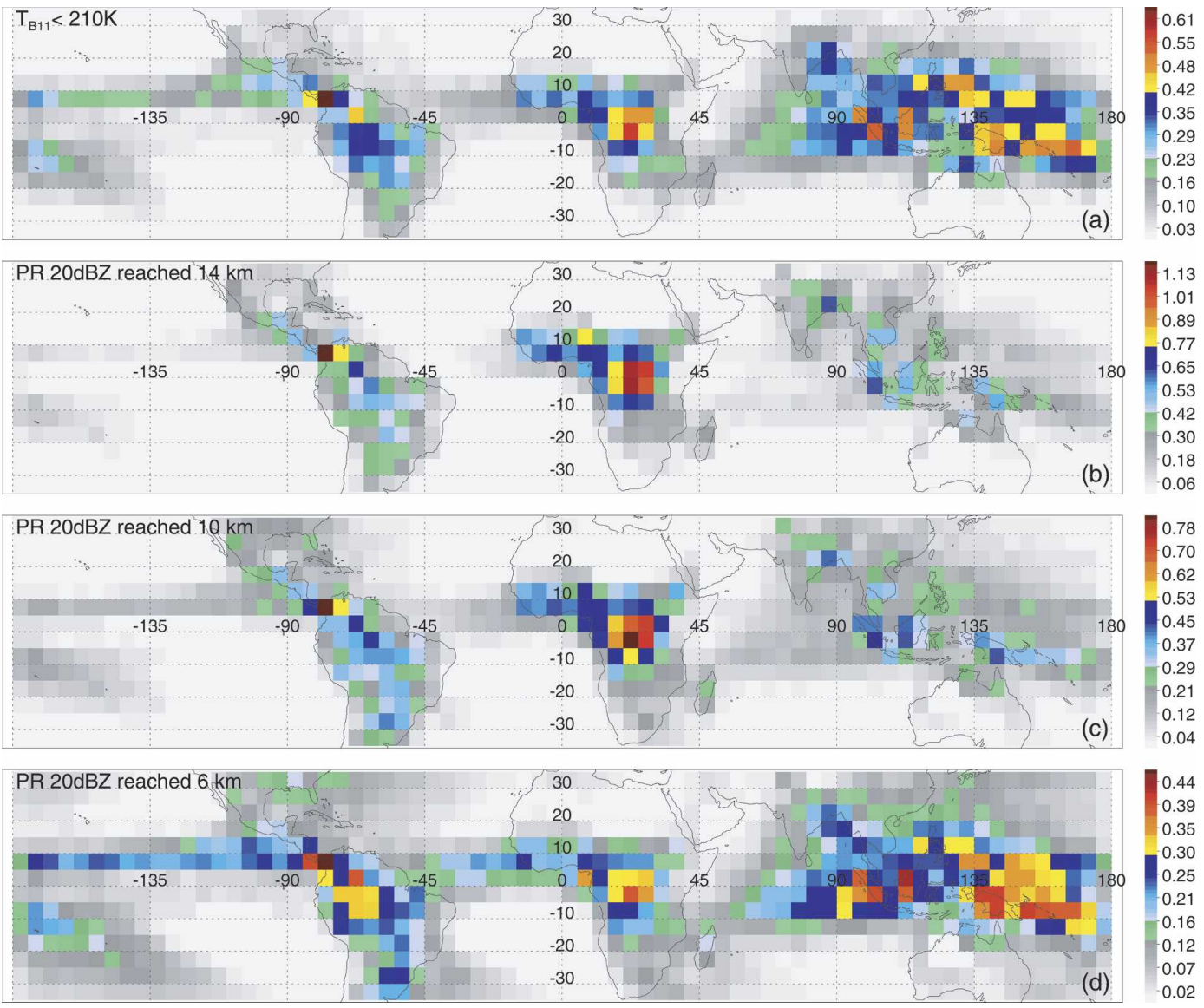

FIG. 7. (a) Global distribution of the relative contribution from different regions to the total area of $T_{\mathrm{B} 11} \leq 210$ $\mathrm{K}$, and area of PR $20 \mathrm{dBZ}$ reaching (b) 14 , (c) 10 , and (d) $6 \mathrm{~km}$ within those CCFs ( $\leq 210 \mathrm{~K}$ ) between $35^{\circ} \mathrm{N}$ and $35^{\circ} \mathrm{S}$. The area in each $5^{\circ} \times 5^{\circ}$ bin has been divided by TRMM $3 \mathrm{~A} 25$ total pixel number to remove the sampling bias. The values in each panel add up to $100 \%$. Units are \%.

2006). The seasonal cycle of the most extreme CCFs from Fig. 8 is shown in Fig. 9. There is an obvious seasonal migration of the African and Indian monsoon systems. The highest $20-\mathrm{dB} Z$ tops favor land, while the coldest clouds favor the tropical west Pacific. It is interesting to note that most of the coldest clouds in the equatorial west Pacific occur in northern winter and spring when the tropopause is higher than in other seasons.

To quantify the height difference between the cloud top indicated by the coldest IR temperature and the 20-dBZ echo top, cloud-top heights of CCFs $\left(T_{\mathrm{B} 11} \leq\right.$ $210 \mathrm{~K})$ are calculated with the minimum $T_{\mathrm{B} 11}$ using the NCEP reanalysis temperature profile. Then, the distance to the CCF's maximum 20-dBZ height is averaged in $5^{\circ} \times 5^{\circ}$ boxes. This procedure is duplicated for different seasons and shown in Fig. 10. In general, the distances between cloud top and the $20-\mathrm{dB} Z$ top are smaller over land than over ocean. Central Africa has the smallest distances. The largest distances are over the Indian Ocean during northern summer and spring, SPCZ southern summer, and west Pacific northern summer.

We should note that the TRMM PR swath width (215 $\mathrm{km}$ before orbit boost and $247 \mathrm{~km}$ after) necessarily cuts off some of the CCFs at the swath edge. Therefore, it is possible that convective cores can be outside the PR swath. Also, the distance between the $20-\mathrm{dB} Z$ top and the IR top will vary with stage of the life cycle of the convection. The distances shown in Fig. 10 therefore represent a statistical mean taking into account these factors for each region.

Despite these caveats, there are such clear distinctions between regions in Fig. 10 that we believe smaller differences between the $20-\mathrm{dB} Z$ top and the IR top are indicative of cloud systems containing stronger convective cores, lofting larger particles closer to cloud top, where they are detectable by the PR. For example, convection in Central Africa is generally stronger than that in equatorial South America, a conclusion reached by 

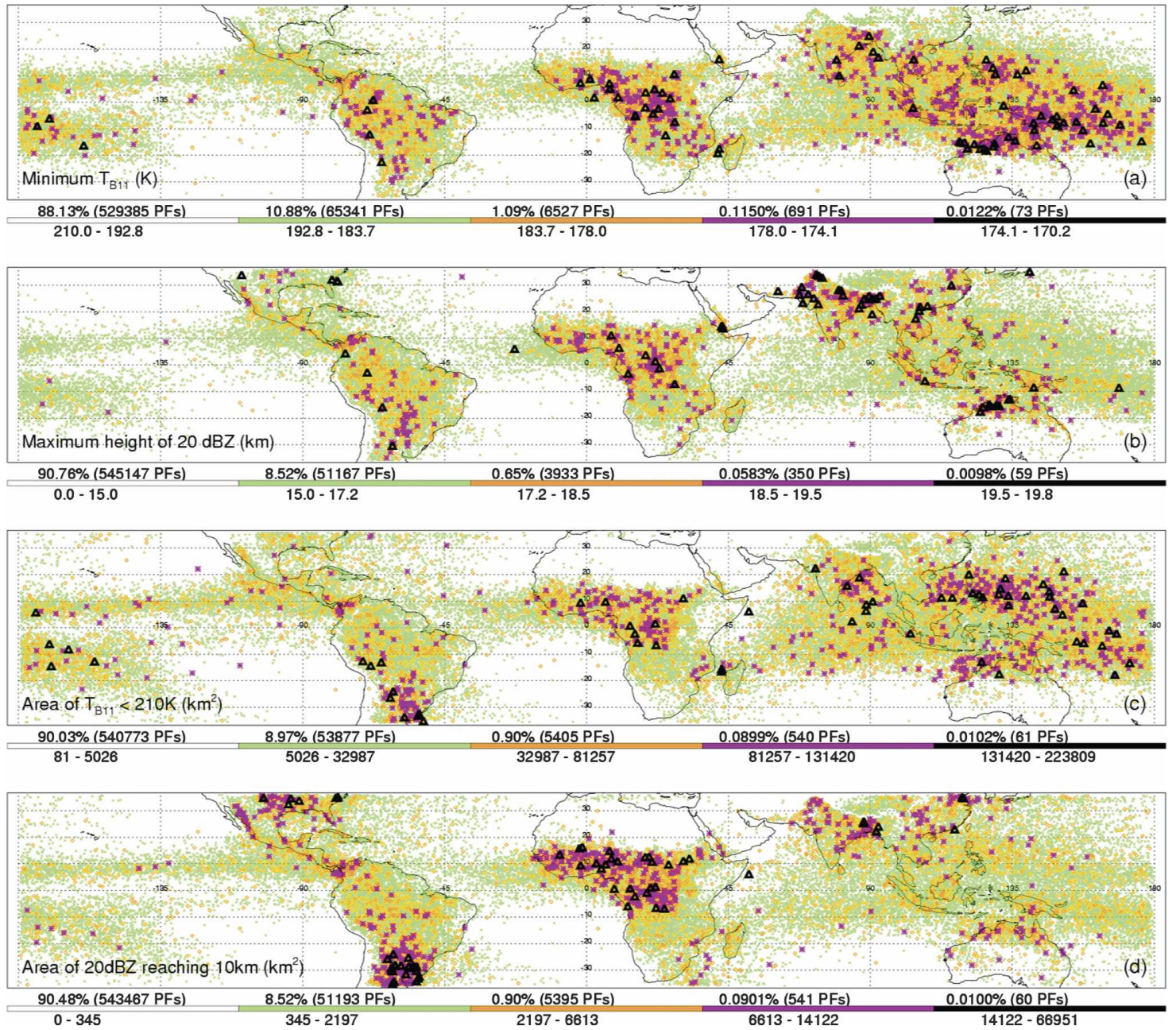

FIG. 8. Location of CCFs $\left(\leq 210 \mathrm{~K}\right.$ ) categorized by coldest $T_{\mathrm{B} 11}$, maximum 20 -dBZ height, size of $T_{b} \leq 210 \mathrm{~K}$, and size of $20 \mathrm{~dB} Z$ reaching $10 \mathrm{~km}$. Rarity of the events are represented with green ( $\sim$ top $10 \%)$, orange ( $\sim$ top $1 \%)$, purple ( top $0.1 \%)$, and black ( $\sim$ top $0.01 \%)$ symbols.

others (Petersen and Rutledge 2001; Petersen et al. 2005). Some of the seasonal variations (not shown) are also consistent with previous studies, for example, the inferred stronger storms in eastern India during the premonsoon months [March-May (MAM)] than during the heart of the monsoon rains in June-August (JJA).

\section{c. Discussion}

In the previous sections, the differences in the global distribution of properties of deep convection viewed from IR and radar are shown. On average, only onethird of the area occupied by clouds $\leq 235 \mathrm{~K}$ has rain detected by radar. A relatively larger proportion of nonraining clouds occurs over Central Africa than over most oceans. Speculation is that intense deep convection over Central Africa may create larger anvils in proportion to rain area than the relatively weaker con- vection over oceans (e.g., Nesbitt et al. 2000; Cecil et al. 2005). However, further investigation is needed to support this speculation. Over the west Pacific, there is a large area of IR-detected cold clouds, but a smaller area proportion of radar echoes above $10 \mathrm{~km}$. The radar echo top extends closer to the height of the cloud top inferred from IR brightness temperature over land than over ocean.

While deep convective towers with powerful updrafts may overshoot the level of neutral buoyancy (LNB) considerably, extensive cirrus anvils produced from those clouds will generally spread out close to the LNB. In most of the deep Tropics, the LNB varies rather little (not shown). It is generally higher in the tropical west Pacific than elsewhere, which may account for the abundant high clouds there. Using the NCEP thermodynamic data in the vicinity of CCFs, we construct sche- 

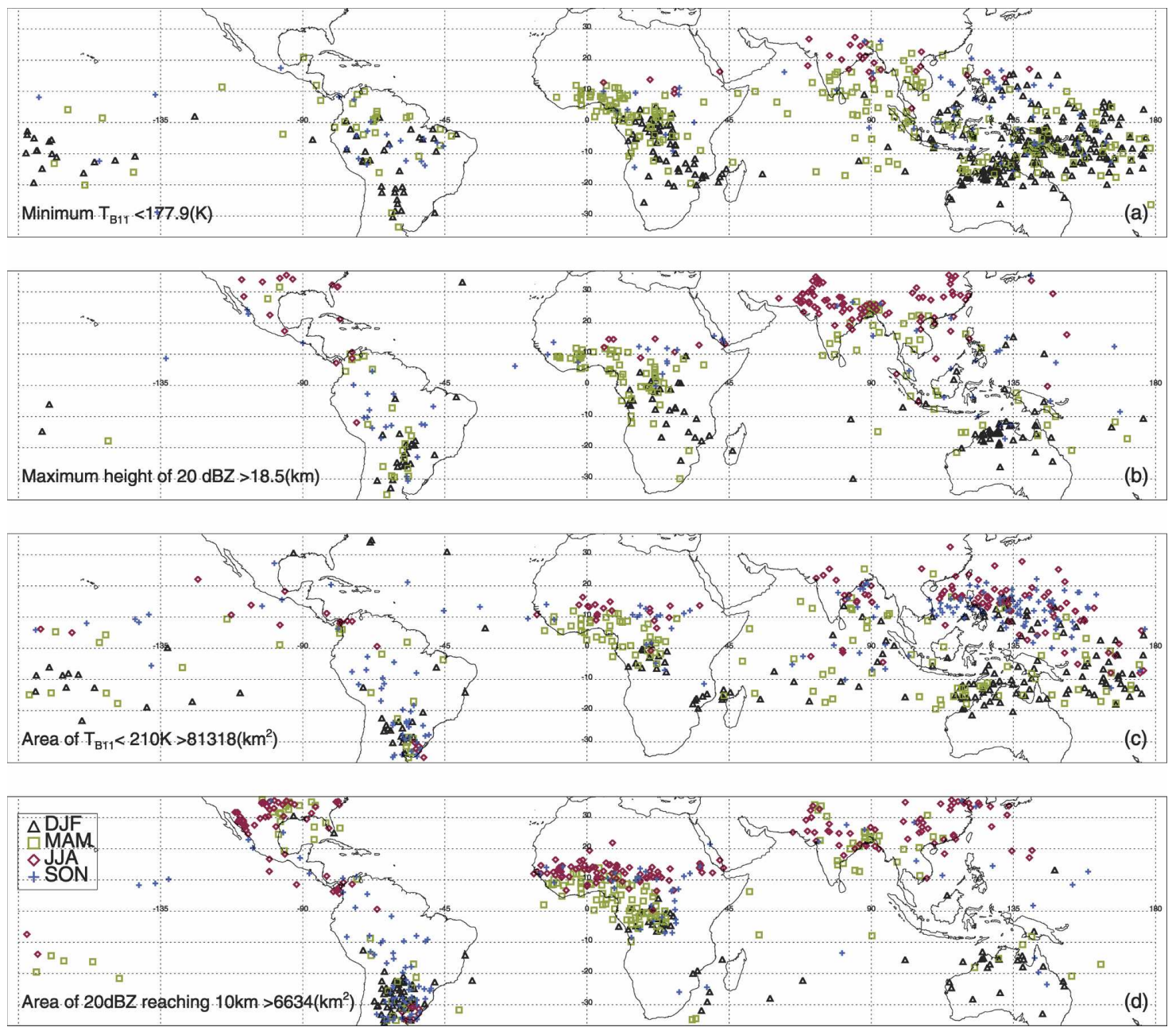

FIG. 9. Color- and symbol-coded seasonal cycle of the most extreme events (purple and black categories in Fig. 8).

matic diagrams of the perceived contrasts between CCFs over Central Africa and the tropical west Pacific. Figure 11 shows different distributions of the LNB in the two regions; we assume that the CCFs of interest occur with LNB near the modal values of $14.18 \mathrm{~km}$ for Africa and $14.44 \mathrm{~km}$ for the Pacific.

In Fig. 12, we contrast assumed "typical" convective systems over Central Africa and the tropical west Pacific, using the statistics for each region summarized in Table 2.

There is abundant evidence that typical updrafts are much stronger over Congo (Zipser et al. 2006), lofting larger particles high into the storm, resulting in the 20$\mathrm{dB} Z$ radar echo tops exceeding $14 \mathrm{~km}$ over 5 times the area as over the tropical Pacific (Liu and Zipser 2005). This is still a tiny fraction of the area of $\leq 210 \mathrm{~K}$ IR tops. It is commonly observed that intense storms have anvils that are optically thick compared with geometrical thickness, which we speculate accounts for comparable coverage of cold IR tops while fractional area of radardetected rain is less over Central Africa. Higher cloud bases over land are inferred to result in greater evaporation of rain (McCollum et al. 2000), while abundant warm rain regions and less subcloud evaporation add to the rain area over oceans.

In addition to the discussion above, these results suggest the following:

- "Deep" convection is sometimes used as a synonym for "intense" convection. This is probably not accurate because the same deep cold cloud may be generated from different convective intensities in different environments. (cf. Nesbitt et al. 2006).

- When using the TRMM radar profiles to study the vertical structure of cloud systems in the troposphere, it is important to remember that there is a large depth of ice clouds undetectable by the PR. Especially over 

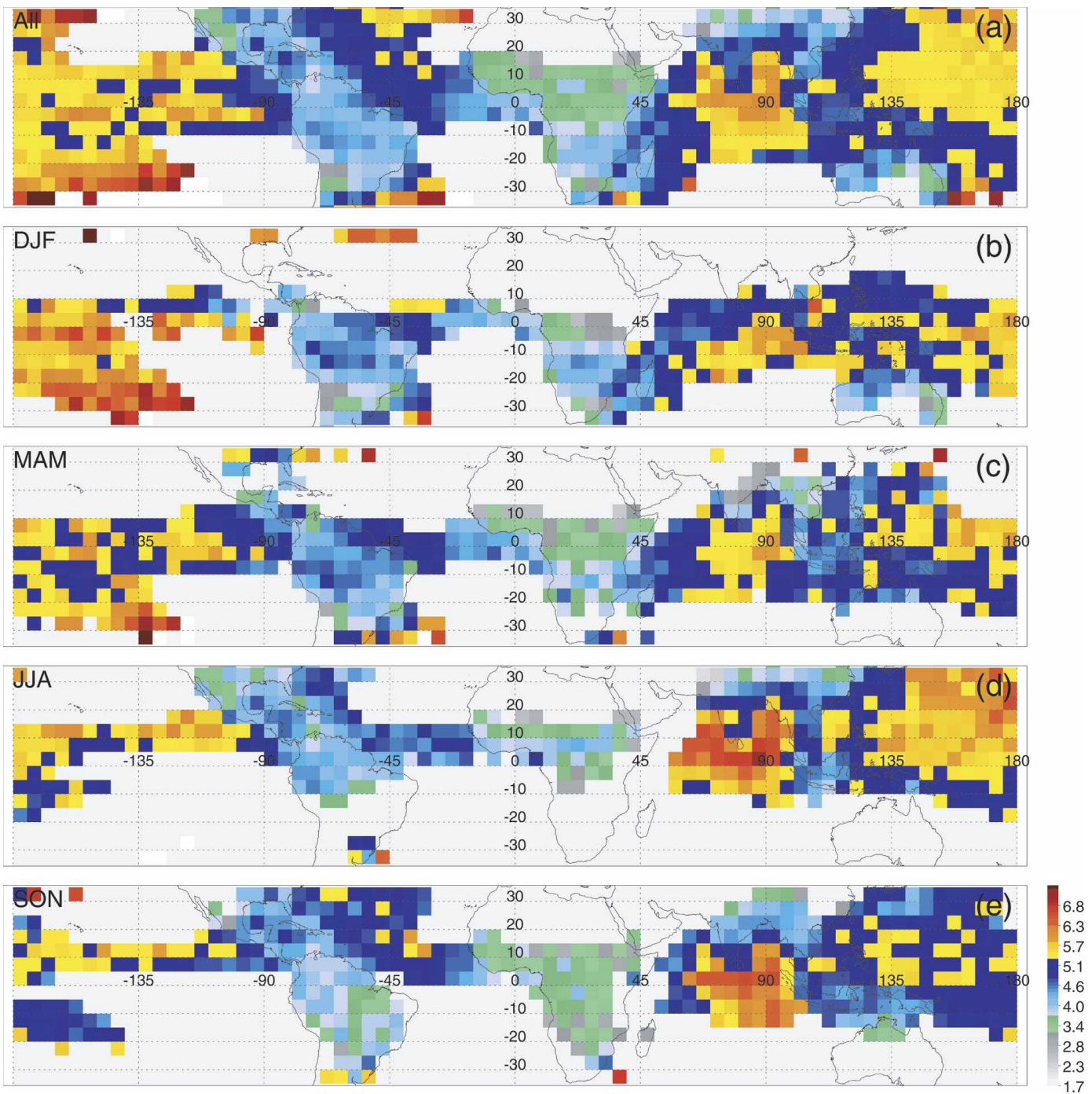

FIG. 10. The mean differences of cloud-top height calculated from minimum $T_{\mathrm{B} 11}$ and the maximum 20-dBZ echo-top height for CCFs $(\leq 210 \mathrm{~K}$ with $2 \mathrm{~A} 25 \mathrm{rain})$ in $5^{\circ} \times 5^{\circ}$ boxes and their seasonal variations. Units are height differences in $\mathrm{km}$ that the $20-\mathrm{dBZ}$ echo top is below the IR top height.

ocean, the distance between cloud top and maximum 20 -dBZ height is often $6 \mathrm{~km}$ or even greater.

- Based upon the regional and seasonal variability in this study, relating tropical deep convection to troposphere-stratosphere exchange may require further understanding of the intensity of convective systems impacting the tropical tropopause layer (TTL; 14-18 $\mathrm{km}$ from Sherwood and Dessler 2000). Other things being equal, the more intense the convection, the closer the radar echo top is likely to be to the IR top, and the larger the potential for mass exchange in the TTL (Liu and Zipser 2005).

- These findings may explain the land ocean differences in mesoscale convective complex (MCC; Maddox 1980) populations (reported by Laing and Fritsch
1997), which were found to occur mostly over land, and radar-defined monsoon covective system (MCS) populations (Nesbitt et al. 2006), which were found to occur with relative equity over land and ocean. Despite cold CCFs present over land and ocean, the results of this paper indicate that strong and/or longlasting convective system updrafts (found preferentially over land) may be necessary to spread sufficient condensate into anvils to meet the MCC size, duration, and shape criteria.

\section{Summary}

Using six years of TRMM VIRS and PR measurements, clouds colder than $235 \mathrm{~K}$ are grouped, and the 


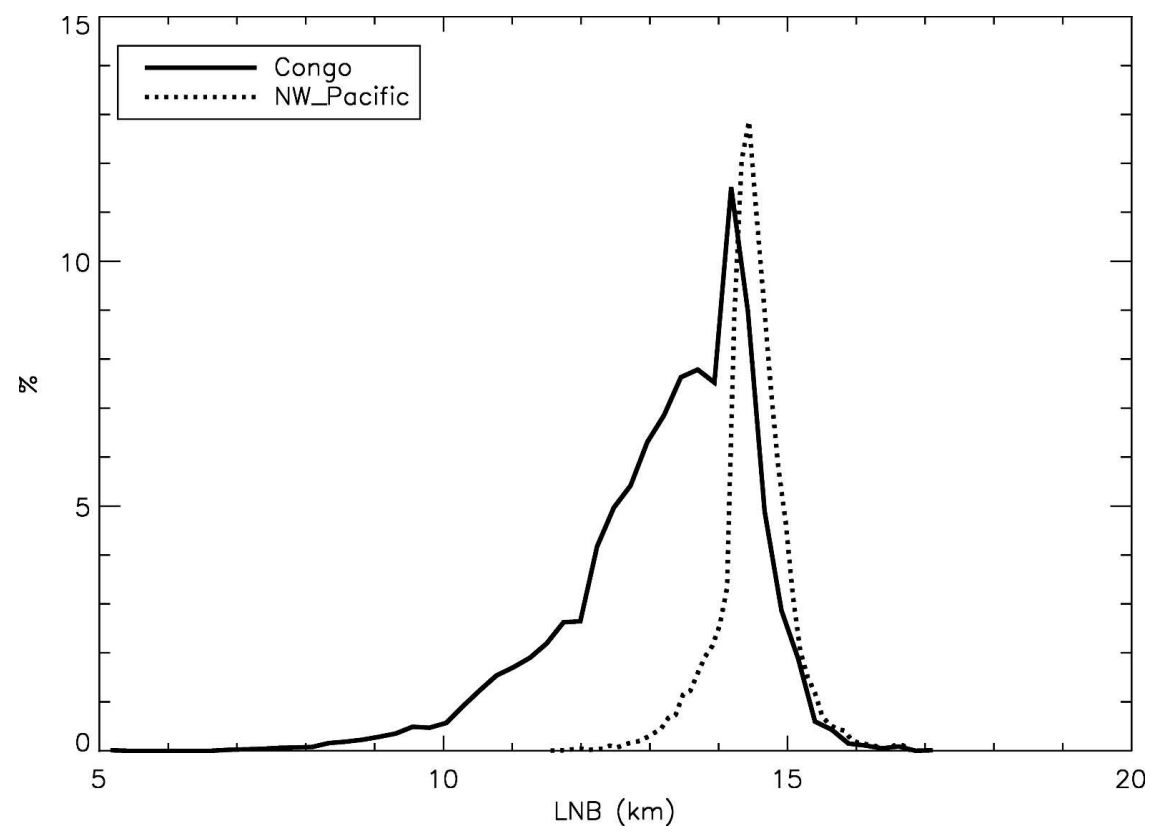

FIG. 11. Relative frequency of level of neutral buoyancy in Central Africa (Congo, $10^{\circ} \mathrm{S}-$ $\left.5^{\circ} \mathrm{N}, 15^{\circ}-30^{\circ} \mathrm{E}\right)$ and the northwestern tropical Pacific $\left(0^{\circ}-15^{\circ} \mathrm{N}, 135^{\circ}-170^{\circ} \mathrm{E}\right)$. The modal values are 14.18 and $14.44 \mathrm{~km}$, respectively.

characteristics of convection from IR and PR observations are summarized. After separating the cold cloud with and without rain detected by the PR, there are large differences between the proportional nonraining cloud amounts over land and that over ocean. Rain estimates of GPI are corrected with raining area ratios. Better distribution consistency suggests that part of the discrepancy between rain estimates of GPI and TRMM 3A25 may be explained by the nonraining cold clouds (i.e., anvils). The global distribution of area of clouds with IR $T_{b} \leq 210 \mathrm{~K}$, and $20-\mathrm{dBZ}$ radar echo at 10 and $14 \mathrm{~km}$, shows that large areas of cold clouds are found over the west Pacific, while the radar echoes reaching high altitudes are detected mostly over land. The cold-

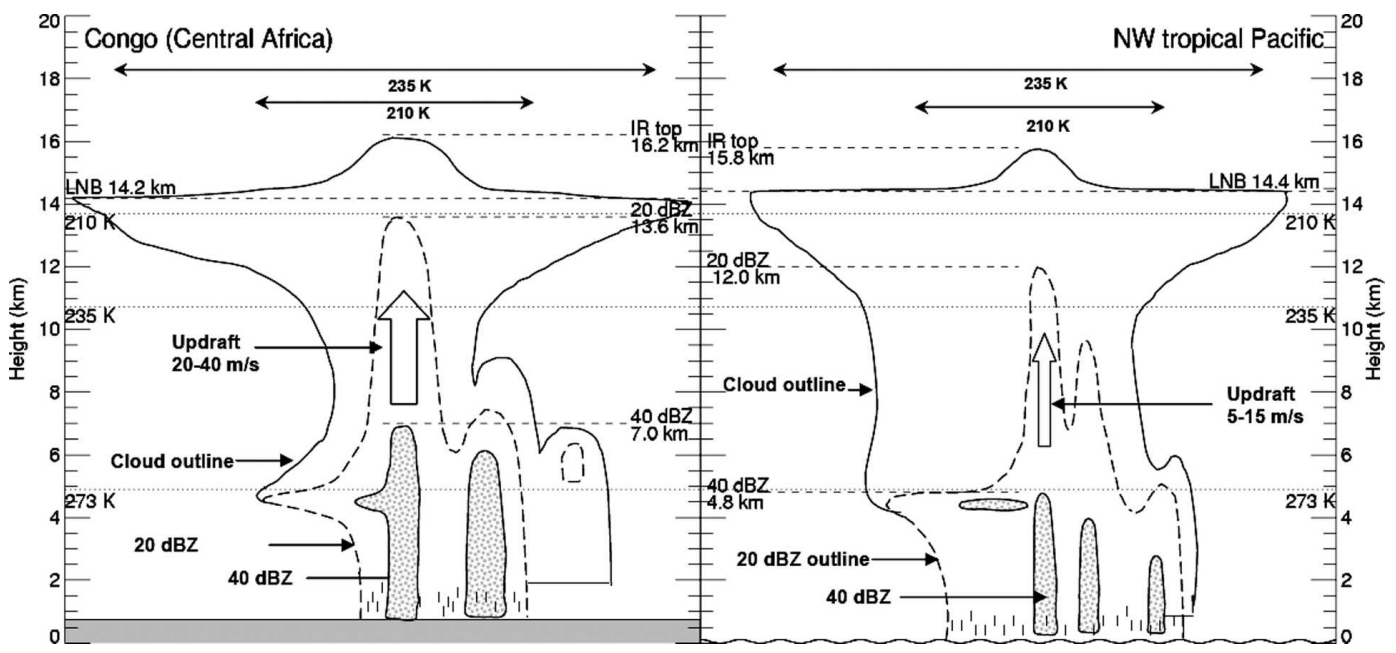

FIG. 12. Schematic of the structure of deep convection (CCF with $T_{\mathrm{B} 11} \leq 210 \mathrm{~K}$ ) over Central Africa and the northwestern tropical Pacific, demonstrating differences between typical strong systems in the two regions. Modal values of LNB are as in Fig. 11. Heights derived from IR observations, 20- and 40-dBZ echo-top heights; relative coverage of radar echoes $>20 \mathrm{dBZ}$ at 6,10 , and $14 \mathrm{~km}$ are taken from the 6-yr database of TRMM CCFs discussed in the text. 
TABLE 2. Mean characteristics of CCFs $(\leq 235 \mathrm{~K})$ with minimum $T_{\mathrm{B} 11}<210 \mathrm{~K}$ and at least one pixel of $40 \mathrm{dBZ}$ in Congo $\left(10^{\circ} \mathrm{S}-5^{\circ} \mathrm{N}, 15^{\circ}-32^{\circ} \mathrm{E}\right)$ and northwest tropical Pacific $\left(0^{\circ}-15^{\circ} \mathrm{N}\right.$, $\left.135^{\circ}-170^{\circ} \mathrm{E}\right)$.

\begin{tabular}{lcc}
\hline \hline \multicolumn{1}{c}{$\%$ of area $\leq 235 \mathrm{~K}$} & Congo & $\begin{array}{c}\text { Northwest } \\
\text { Pacific }\end{array}$ \\
\hline Area $\leq 210 \mathrm{~K}(\%)$ & 31.5 & 27.9 \\
Area of $20 \mathrm{dBZ}$ reaching $14 \mathrm{~km} \mathrm{( \% )}$ & 0.67 & 0.12 \\
Area of $20 \mathrm{~dB} Z$ reaching $10 \mathrm{~km} \mathrm{( \% )}$ & 4.2 & 1.2 \\
Area of 20 dBZ reaching 6 km (\%) & 22.5 & 22.3 \\
Area of PR 2A25 rain $(\%)$ & 34.7 & 45.1 \\
Mean surface elevation $(\mathrm{km})$ & 0.75 & 0.0 \\
Mean IR top height $(\mathrm{km})$ & 16.2 & 15.8 \\
Mean 20-dBZ height $(\mathrm{km})$ & 13.6 & 12.0 \\
Mean 40-dBZ height $(\mathrm{km})$ & 7.0 & 4.8 \\
Modal LNB height $(\mathrm{km})$ & 14.18 & 14.44 \\
\hline
\end{tabular}

est clouds cover the largest area in the Tropics over the west Pacific. However, the systems with largest area of $20 \mathrm{dBZ}$ at and above $10 \mathrm{~km}$ are mostly over continental regions, especially Central Africa. Mean distances between IR-inferred cloud tops and radar echo tops are greater over ocean than over land. The smallest distance was found over Central Africa. We hypothesize that high LNB over the west Pacific permits even weak convection to produce deep cold clouds without 20$\mathrm{dBZ}$ echoes above $10 \mathrm{~km}$. Over land, convection with strong updrafts may lift large particles to high altitudes and overshoot large distances from the LNB to cause cold cloud-top temperature and high radar reflectivity above $10 \mathrm{~km}$.

Acknowledgments. This research was supported by NASA Precipitation Measurement Mission Grants NAG5-13628 (CL and EZ) and NAG5-13623 (SN) under the direction of Dr. Ramesh Kakar, and by UIUC faculty startup funds. Special thanks go to Drs. Erich Stocker and John Kwiatkowski and the rest of the TRMM Science Data and Information System (TDSIS) at the NASA Goddard Space Flight Center, Greenbelt, Maryland, for data-processing assistance.

\section{REFERENCES}

Cecil, D. J., S. J. Goodman, D. J. Boccippio, E. J. Zipser, and S. W. Nesbitt, 2005: Three years of TRMM precipitation features. Part I: Radar, radiometric, and lightning characteristics. Mon. Wea. Rev., 133, 543-566.

Chen, S. S., R. A. Houze, and B. E. Mapes, 1996: Multiscale variability of deep convection in relation to large-scale circulation in TOGA COARE. J. Atmos. Sci., 53, 1380-1409.

Cifelli, E., W. A. Peterson, L. D. Carey, S. A. Rutledge, and M. A. F. Silva Dias, 2002: Radar observations of the kinematic, microphysical, and precipitation characteristics of two
MCSs in TRMM LBA. J. Geophys. Res., 107, 8077, doi:10.1029/2000JD000264.

Cifelli, R., S. W. Nesbitt, S. A. Rutledge, W. A. Petersen, and S. E. Yuter, 2007: Radar characteristics of precipitation features in the EPIC and TEPPS regions of the East Pacific. Mon. Wea. Rev., in press.

DeMott, C. A., and S. A. Rutledge, 1998: The vertical structure of TOGA COARE convection. Part I: Radar echo distributions. J. Atmos. Sci., 55, 2730-2747.

Gettelman, A., M. L. Salby, and F. Sassi, 2002: The distribution and influence of convection in the tropical tropopause region. J. Geophys. Res., 107, 4080, doi:10.1029/2001JD001048.

Hall, T. J., and T. H. Vonder Haar, 1999: The diurnal cycle of west Pacific deep convection and its relation to the spatial and temporal variations of tropical MCSs. J. Atmos. Sci., 56, 3401-3415.

Heymsfield, G. M., and R. Fulton, 1988: Comparison of highaltitude remote aircraft measurements with the radar structure of an Oklahoma thunderstorm: Implications for precipitation estimation from space. Mon. Wea. Rev., 116, 11571174.

- J. M. Shepherd, S. W. Bidwell, W. C. Boncyk, I. J. Caylor, S. Ameen, and W. S. Olson, 1996: Structure of Florida thunderstorms using high-altitude aircraft radiometer and radar observations. J. Appl. Meteor., 35, 1736-1762.

Holton, J. R., P. H. Haynes, M. E. McIntyre, A. R. Douglass, R. B. Rood, and L. Pfister, 1995: Stratosphere-troposphere exchange. Rev. Geophys., 33, 403-439.

Hong, G., G. Heygster, J. Miao, and K. Kunzi, 2005: Detection of tropical deep convective clouds from AMSU-B water vapor channels measurements. J. Geophys. Res., 110, D05205, doi:10.1029/2004JD004949.

Huffman, G., R. Adler, M. Morrissey, D. Bolvin, S. Cuttis, R. Joyce, B. McGavock, and J. Susskind, 2001: Global precipitation at one-degree daily resolution from multisatellite observations. J. Hydrometeor., 2, 36-50.

Iguchi, T., T. Kozu, R. Meneghini, J. Awaka, and K. Okamoto, 2000: Rain-profiling algorithm for the TRMM precipitation radar. J. Appl. Meteor., 39, 2038-2052.

Jiang, J. H., B. Wang, K. Goya, K. Hocke, S. F. Eckermann, J. Ma, D. L. Wu, and W. G. Read, 2004: Geographical distribution and interseasonal variability of tropical deep convection: UARS MLS observations and analyses. J. Geophys. Res., 109, D03111, doi:10.1029/2003JD003756.

Joyce, R., and P. A. Arkin, 1997: Improved estimates of tropical and subtropical precipitation using the GOES Precipitation Index. J. Atmos. Oceanic Technol., 10, 997-1011.

Kistler, R., and Coauthors, 2001: The NCEP-NCAR 50-Year Reanalysis: Monthly means CD-ROM and documentation. Bull. Amer. Meteor. Soc., 82, 247-267.

Kummerow, C., W. Barnes, T. Kozu, J. Shiue, and J. Simpson, 1998: The Tropical Rainfall Measuring Mission (TRMM) sensor package. J. Atmos. Oceanic Technol., 15, 809-817.

- , and Coauthors, 2001: The evolution of the Goddard Profiling Algorithm (GPROF) for rainfall estimation from passive microwave sensors. J. Appl. Meteor., 40, 1801-1820.

Laing, A. G., and J. M. Fritsch, 1997: The global population of mesoscale convective complexes. Quart. J. Roy. Meteor. Soc., 123, 389-405.

Liu, C., and E. J. Zipser, 2005: Global distribution of convection penetrating the tropical tropopause. J. Geophys. Res., 110, D23104, doi:10.1029/2005JD006063.

Machado, L. A. T., W. B. Rossow, R. L. Guedes, and A. W. 
Walker, 1998: Life cycle variations of mesoscale convective systems over the Americas. Mon. Wea. Rev., 126, 1630-1654.

Maddox, R. A., 1980: An objective technique for separating macroscale and mesoscale features in meteorological data. Mon. Wea. Rev., 108, 1108-1121.

Mapes, B. E., and R. A. Houze, 1993: Cloud clusters and superclusters over the oceanic warm pool. Mon. Wea. Rev., 121, 1398-1416.

McCollum, J., A. Gruber, and M. B. Ba, 2000: Discrepancy between gauges and satellite estimates of rainfall in equatorial Africa. J. Appl. Meteor., 39, 666-679.

Mohr, K. I., and E. J. Zipser, 1996: Defining mesoscale convective systems by their $85-\mathrm{GHz}$ ice-scattering signatures. Bull. Amer. Meteor. Soc., 77, 1179-1189.

Nesbitt, S. W., E. J. Zipser, and D. J. Cecil, 2000: A census of precipitation features in the Tropics using TRMM: Radar, ice scattering, and lightning observations. J. Climate, 13, 40874106.

—, R. Cifelli, and S. A. Rutledge, 2006: Storm morphology and rainfall characteristics of TRMM precipitation features. Mon. Wea. Rev., 134, 2702-2721.

Petersen, W. A., and S. A. Rutledge, 2001: Regional variability in tropical convection: Observations from TRMM. J. Climate, 14, 3566-3586.

— - H. J. Christian, and S. A. Rutledge, 2005: TRMM observations of the global relationship between ice water content and lightning. Geophys. Res. Lett., 32, L14819, doi:10.1029/ 2005 GL023236.

Riehl, H., and J.S. Malkus, 1958: On the heat balance in the equatorial trough zone. Geophysica, 6, 503-538.

Rossow, W. B., and R. A. Schiffer, 1999: Advances in understand- ing clouds from ISCCP. Bull. Amer. Meteor. Soc., 80, 22612287.

Rudolf, B., 1993: Management and analysis of precipitation data on a routine basis. Proc. Int. WMO/IAHS/ETH Symp. on Precipitation and Evaporation, Bratislava, Slovakia, Slovak Hydrometeorology Institute, 69-76.

Schumacher, C., and R. A. Houze, 2003: Stratiform rain in the Tropics as seen by the TRMM precipitation radar. J. Climate, 16, 1739-1756.

Sherwood, S. C., and A. E. Dessler, 2000: On the control of stratospheric humidity. Geophys. Res. Lett., 27, 2513-2516.

Spencer, R. W., H. G. Goodman, and R. E. Hood, 1989: Precipitation retrieval over land and ocean with the SSM/I: Identification and characteristics of the scattering signal. J. Atmos. Oceanic Technol., 6, 254-273.

Toracinta, E. R., and E. J. Zipser, 2001: Lightning and SSM/I-icescattering mesoscale convective systems in the global Tropics. J. Appl. Meteor., 40, 983-1002.

Tian, B. J., B. J. Soden, and X. Wu., 2004: Diurnal cycle of convection, clouds, and water vapor in the tropical upper troposphere: Satellites versus a general circulation model. J. Geophys. Res., 109, D10101, doi:10.1029/2003JD004117.

Vicente, G. A., R. A. Scofield, and W. P. Menzil, 1998: The operational GOES infrared rainfall estimation technique. Bull. Amer. Meteor. Soc., 79, 1883-1898.

Zipser, E. J., D. Cecil, C. Liu, S. Nesbitt, and D. Yorty, 2006: Where are the most intense thunderstorms on earth? Bull. Amer. Meteor. Soc., 87, 1057-1071.

Zuidema, P., 2003: Convective clouds over the Bay of Bengal. Mon. Wea. Rev., 131, 780-798. 